\title{
Carbonylation of Epoxides to Substituted 3-Hydroxy-ס-Lactones
}

\author{
John W. Kramer, Daniel Y. Joh, and Geoffrey W. Coates * \\ Department of Chemistry and Chemical Biology, Baker Laboratory, Cornell University, Ithaca, NY \\ 14853-1301
}

Abstract

Substituted 3-hydroxy- $\delta$-lactones (3HLs) are valuable intermediates in the synthesis of pharmaceuticals and other biologically active natural products. Herein we report the first example of the catalytic carbonylation of substituted homoglycidols to $3 \mathrm{HLs}$ using $\mathrm{HCo}(\mathrm{CO})_{4}$. Upon optimization of the catalyst and reaction conditions, a functionally diverse set of $3 \mathrm{HLs}$ was prepared. Mechanistic insight was gained by observation of the carbonylation reaction using in situ IR spectroscopy, and we propose a mechanism that is consistent with previously studied epoxide carbonylation systems.

Substituted 3-hydroxy- $\delta$-lactones (3HLs) are common structural motifs in natural products ${ }^{1}$ and are valuable as intermediates in the synthesis of a variety of pharmaceutical compounds. $2,3,4,53 \mathrm{HLs}$ are most prominent in the class of HMG-CoA reductase inhibitors known as statins, which are among the most potent cholesterol-lowering drugs available and constitute five of the top 100 selling drugs. ${ }^{5}$ All approved statins have side chains comprised of either a 3HL or the hydrolyzed 3,5-dihydroxycarboxylic acid analog (Figure 1), which are essential for the bioactivity of statin drugs. ${ }^{6}$ 3HLs have also been used in the synthesis of important drugs such as tetrahydrolipstatin, 2 a lipase inhibitor prescribed for the treatment of obesity, and the antiretroviral agent tipranavir. ${ }^{3}$ Furthermore, dehydration of 3 HLs produces a class of biologically active $\alpha, \beta$-unsaturated lactone natural products. ${ }^{4}$ As a result of their synthetic value, the synthesis of $3 \mathrm{HLs}$ has received a great deal of attention in recent years. ${ }^{7-10}$ Biocatalytic routes have proven successful in the synthesis of statin side chains, though substrate scope is limited. ${ }^{7}$ Synthetic routes to substituted 3 HLs have employed a variety of methods, including aldol reactions using chiral auxiliaries, ${ }^{8}$ reduction of diketoesters followed by cyclization, ${ }^{1}$ allyl boration and ring-closing metathesis, ${ }^{9}$ and rearrangement of $\beta$-lactones. 10 These methods, however, involve multiple steps and can suffer from low stereoselectivity.

Our laboratory has recently reported a number of catalysts that are active for the carbonylation of a functionally diverse array of epoxides to $\beta$-lactones. ${ }^{11}$ However, the expected $\beta$-lactone was not formed in the carbonylation of glycidol; instead, 3-hydroxy- $\gamma$-valerolactone was the sole product (Scheme 1). ${ }^{12}$ While this method could be utilized in the synthesis of $\gamma$-lactone natural products such as (-)-grandinolide, ${ }^{13}$ this result led us to consider the carbonylation of substituted homoglycidols as a potential route to $3 \mathrm{HLs}$. Such a process would provide simple access to $\delta$-lactones with a variety of substitution starting from commercially available epoxides and aldehydes (Scheme 2). ${ }^{14}$ 
Our initial efforts to carbonylate 4-hydroxy-1,2-epoxynonane (6) ${ }^{15}$ to $\delta$-lactone 7 using known epoxide carbonylation catalysts resulted in mixtures of $\beta$ - and $\delta$-lactones (Table 1, entries 1-6). In general, catalysts that are highly active for epoxide carbonylation to $\beta$-lactone $(\mathbf{1}$ and $\mathbf{3})$ were more selective for $\beta$-lactone (8). This selectivity could be exploited in the synthesis of tetrahydrolipstatin and other $\beta$-lactone-containing lipase inhibitors. ${ }^{2}$ Less active catalysts (2 and 5) produced more $3 \mathrm{HL}$ (7); thus, we reasoned that a catalyst that is active for epoxide ring opening but slow for $\beta$-lactone ring closing would give better selectivity for $3 \mathrm{HL}$. When we used $\mathrm{HCo}(\mathrm{CO})_{4}$ (entry 7 ), which is not known to produce $\beta$-lactones but is effective for the alkoxy carbonylation of epoxides to $\beta$-hydroxy esters, ${ }^{16} 3 \mathrm{HL}$ was formed as the exclusive product.

Our proposed mechanism for the carbonylation of homogylcidols by $\mathrm{HCo}(\mathrm{CO})_{4}(\mathrm{Scheme} 3)$ is analogous to that of other epoxide carbonylations by Lewis acid based catalysts. ${ }^{17}$ The first step involves protonation and ring opening of the epoxide by $\mathrm{HCo}(\mathrm{CO})_{4}$ to form a cobalt alkyl complex. After insertion of $\mathrm{CO}$, the resulting cobalt acyl intermediate can either cyclize to form 3HL (Pathway A) or the more strained $\beta$-lactone (BL; Pathway B). Another potential mechanism for $3 \mathrm{HL}$ formation could involve a BL intermediate and its subsequent rearrangement to $3 \mathrm{HL}$. However, using in situ IR spectroscopy, BL was not observed in the carbonylation of $6 .{ }^{14}$ Furthermore, rearrangement of BL 8 to 3HL 7 was negligible under the reaction conditions, eliminating this mechanistic possibility.

After optimizing the reaction conditions for efficient $\delta$-lactone formation, ${ }^{14}$ a variety of susbstituted homoglycidols were carbonylated (Table 2). ${ }^{15}$ Both alkyl-(entries 1 and 2) and aryl-substituted (entry 3) homoglycidols were carbonylated cleanly to 3HLs. Disubstituted homoglycidols (entries 4-6) produced 7d and the spiro 3HLs 7e and 7f, however a small amount of $\beta$-lactone was also formed in these carbonylations. We believe the more sterically hindered tertiary alcohols undergo slower ring closing, making $\beta$-lactone formation from a secondary alcohol (Scheme 3, pathway B) competitive with 3HL formation. The alkene- and fluoroethersubstituted epoxides (entries 7 and 8 ) required a higher catalyst loading to reach full conversion. Finally, the important synthetic intermediates $\mathbf{7} \mathbf{i}$ and $\mathbf{7} \mathbf{j}$ were synthesized under standard conditions. Both $\mathbf{7 i}$ and $\mathbf{7 j}$ have been used in the synthesis of more complex statin drugs. ${ }^{18,}$ $6 \mathrm{~b}$

The $(3 R, 5 R)$ absolute stereochemistry is essential to the efficacy of statin drugs, $6 \mathrm{~b}$ and the ability to control the stereochemical outcome of the carbonylation is of great importance for any synthetic application. Our proposed mechanism (Scheme 3) predicts retention of stereochemistry of these homoglycidols. To test this mechanistic hypothesis we carbonylated $(\boldsymbol{R}, \boldsymbol{R})$-6b under standard conditions (Figure 2). Analysis by ${ }^{1} \mathrm{H}$ and ${ }^{13} \mathrm{C}$ NMR spectroscopy indicated the trans diastereomer was formed exclusively, and optical rotation established the product as the $(3 R, 5 R)$ isomer. ${ }^{14}$ Thus the carbonylation occurs with retention of both stereocenters.

The synthesis of 3HLs by carbonylation of homoglycidols is an efficient method to access functionally diverse and optically pure lactones. We anticipate the substrate range and simple catalyst preparation will make this procedure useful in a variety of synthetic applications. We are currently applying this methodology to incorporate new functional groups for the synthesis of natural products.

\section{Supplementary Material}

Refer to Web version on PubMed Central for supplementary material. 


\section{Acknowledgements}

We thank Dr. Christopher Byrne (Cornell University) for discussions and materials relating to catalyst preparation. This work was supported by the National Science Foundation (CHE-0243605) and the Department of Energy (DEFG02-05ER15687) and by the National Institutes of Health through a Chemical/Biology Interface (CBI) Training Grant (to J.W.K.).

\section{References}

1. Aggarwal VK, Bae I, Lee HY. Tetrahedron 2004;60:9726-9733.

2. Sharma A, Chattopadhyay S. J Org Chem 1999;64:8059-8062. [PubMed: 11674716]

3. Cefalo DR, Kiely AF, Wuchrer M, Jamieson JY, Schrock RR, Hoveyda AH. J Am Chem Soc 2001;123:3139-3140.

4. Stevenson R, Weber JV. J Nat Prod 1988;51:1215-1219.

5. (a) Tolbert JA. Nat Rev Drug Discov 2003;2:517-526. [PubMed: 12815379] (b) de Lorenzo F, Feher M, Martin J, Collot-Teixeira S, Dotsenko O, McGregor JL. Curr Med Chem 2006;13:3385-3393. [PubMed: 17168712]

6. (a) Ranganathan A, Timoney M, Bycroft M, Cortéz J, Thomas IP, Wilkinson B, Kellenberger L, Hanefeld U, Galloway IS, Staunton J, Leadley PF. Chem Biol 1999;6:731-738. [PubMed: 10508677] (b) Greenberg WA, Varvak A, Hanson SR, Wong K, Huang H, Chen P, Burk M. Proc Natl Acad Sci USA 2004;101:5788-5793. [PubMed: 15069189]

7. (a) Gijsen HJ, Wong CH. J Am Chem Soc 1995;117:7585-7591. (b) Heine A, Luz JG, Wong CH, Wilson IA. J Mol Biol 2004;343:1019-1034. [PubMed: 15476818]

8. (a) Loubinoux B, Sinnes JL, O'Sullivan AC, Winkler T. Tetrahedron 1995;51:3549-3558. (b) Kim SJ, Kang HY, Sherman DH. Synthesis 2001:1790-1793. (c) Le Sann C, Muños DM, Saunders N, Simpson TJ, Smith DI, Soulas F, Watts P, Willis CL. Org Biomol Chem 2005;3:1719-1728. [PubMed: 15858656]

9. Reddy MVR, Brown HC, Ramachandran PV. J Organomet Chem 2001;624:239-243.

10. Fournier L, Gaudel-Siri A, Kocienski PJ, Pons JM. Synlett 2003:107-111.

11. (a) Getzler YDYL, Mahadevan V, Lobkovsky EB, Coates GW. J Am Chem Soc 2002;124:11741175. [PubMed: 11841278] (b) Mahadevan V, Getzler YDYL, Coates GW. Angew Chem Int Ed 2002;41:2781-2784. (c) Schmidt JAR, Mahadevan V, Getzler YDYL, Coates GW. Org Lett 2004;6:373-376. [PubMed: 14748596] (d) Kramer JW, Lobkovsky EB, Coates GW. Org Lett 2006;8:3709-3712. [PubMed: 16898798] (e) Rowley JM, Lobkovsky EB, Coates GW. J Am Chem Soc 2007;129:4948-4960. [PubMed: 17397149]

12. (a) Brima, T. US Patent Application. Chem Abstr 4968817. 1990. p. 185246 (b) Church TL, Getzler YDYL, Byrne CM, Coates GW. Chem Commun 2007:657-674.

13. Zemribo R, Champ MS, Romo D. Synlett 1996:278-280.

14. See Supporting Information.

15. Epoxides 6, 6a-6d, and $\mathbf{6 g - 6 j}$ and their corresponding 3HLs were prepared as a ca. 1:1 mixture of diastereomers. Similar rates of carbonylation were observed for both epoxide diastereomers. ${ }^{13}$

16. Heck RF. J Am Chem Soc 1963;85:1460-1463.

18. MacKeith RA, McCague R, Olivo HF, Roberts SM, Taylor SJC, Xiong H. Bioorg Med Chem 1994;2:387-394. [PubMed: 8000858]

Org Lett. Author manuscript; available in PMC 2008 December 20. 

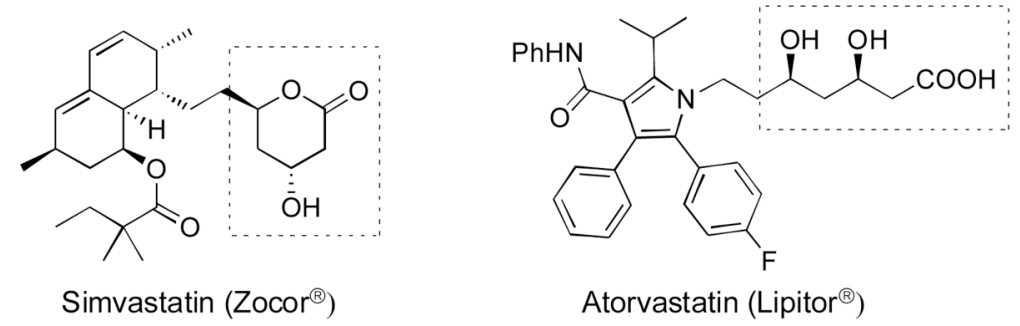

Figure 1.

Structures of two common statin drugs with 3 HL portion highlighted. 


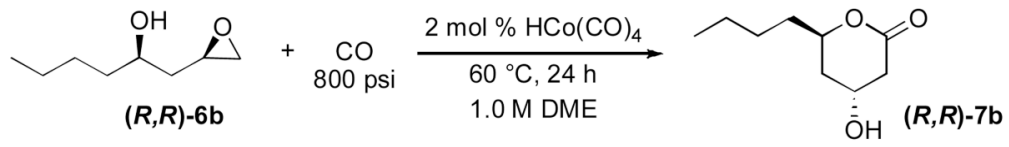

Figure 2.

Carbonylation of enantiopure homoglycidol $(\boldsymbol{R}, \boldsymbol{R})-\mathbf{6 b}$ with retention of stereochemistry. 


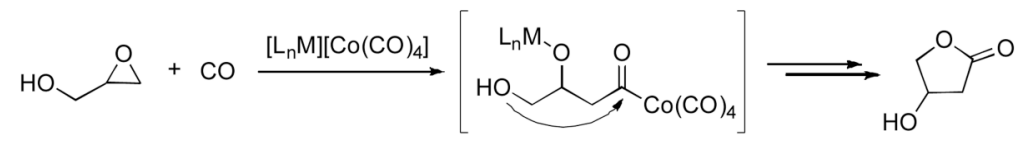

Scheme 1.

Carbonylation of Glycidol to 3-hydroxy- $\gamma$-valerolactone. 


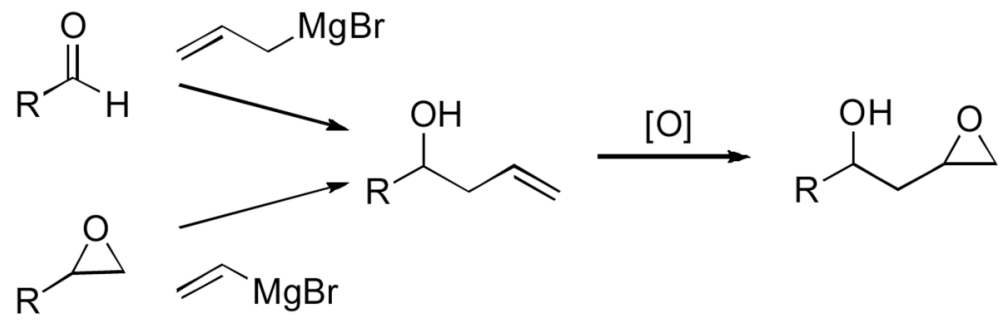

Scheme 2.

Convergent Synthesis of Homoglycidols. 


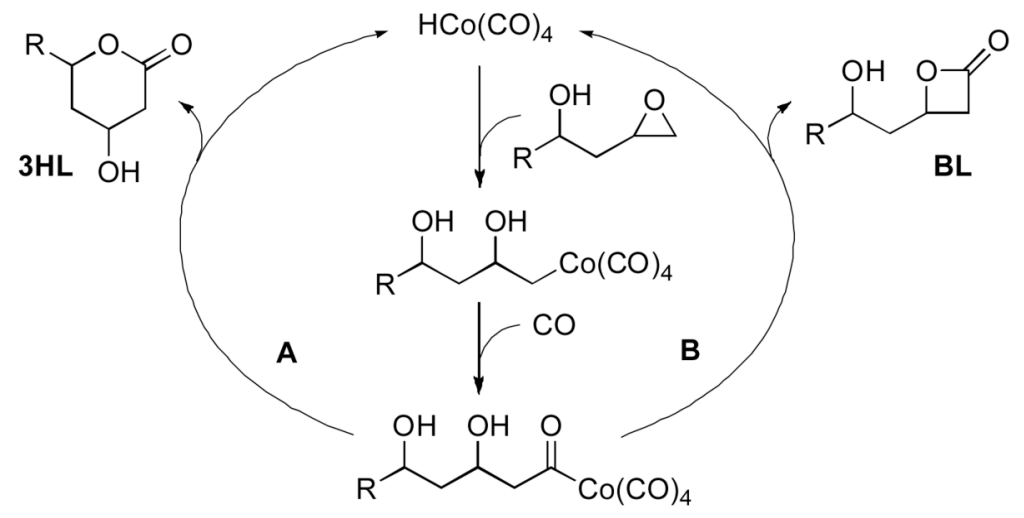

Scheme 3.

Proposed Mechanism for Competing $\delta$-Lactone and $\beta$-Lactone formation. 
Catalyst Screening for 3HL Formation

Table 1

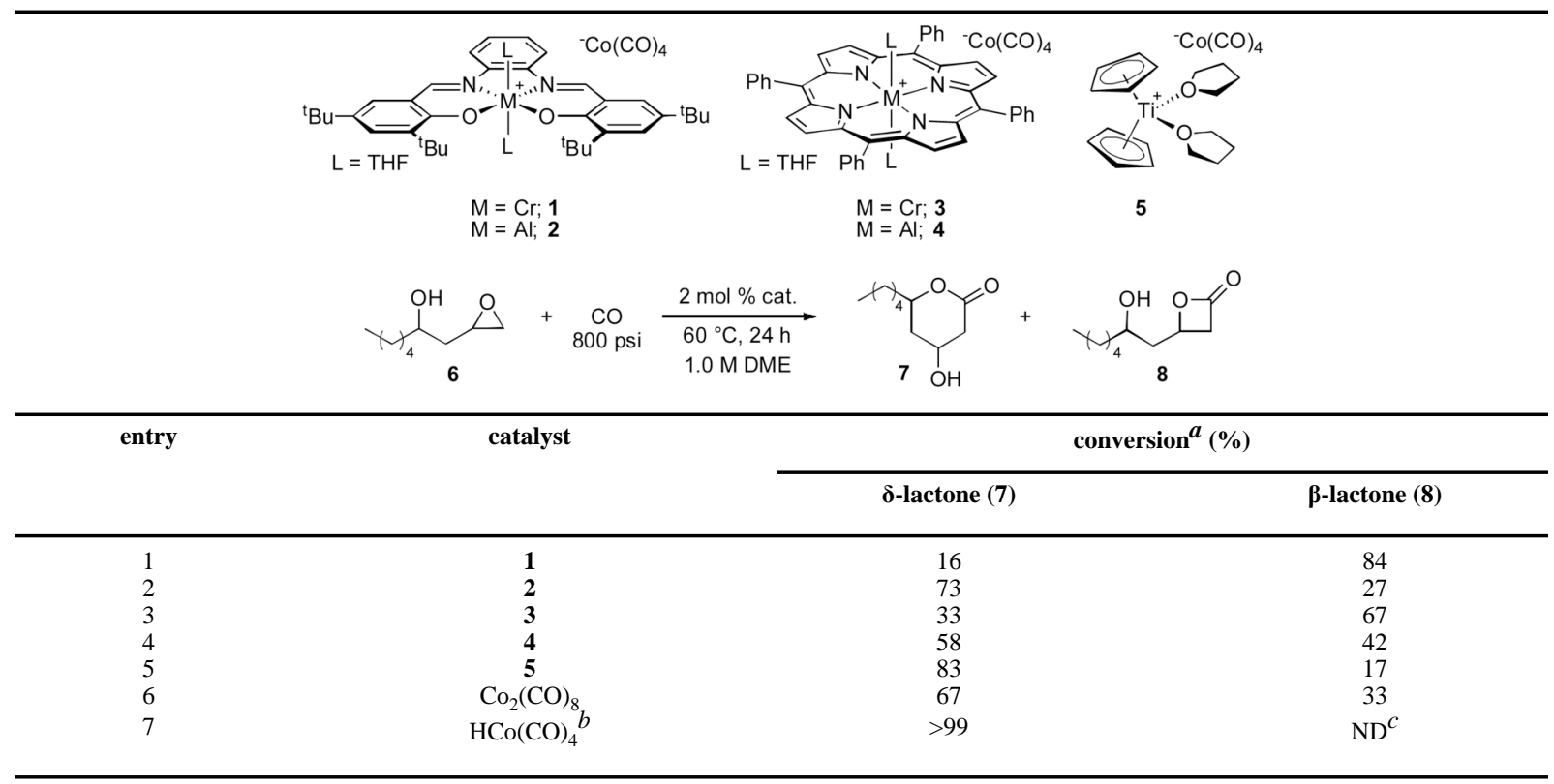

${ }^{a}$ Conversions determined by ${ }^{1}$ H NMR spectroscopy; diastereomeric ratios of $\mathbf{6}, \mathbf{7}$, and $\mathbf{8}$ ca. 1:1.

${ }^{b}$ Prepared in situ; see supporting information for details

${ }^{c} \mathrm{ND}=$ Not Detected. 


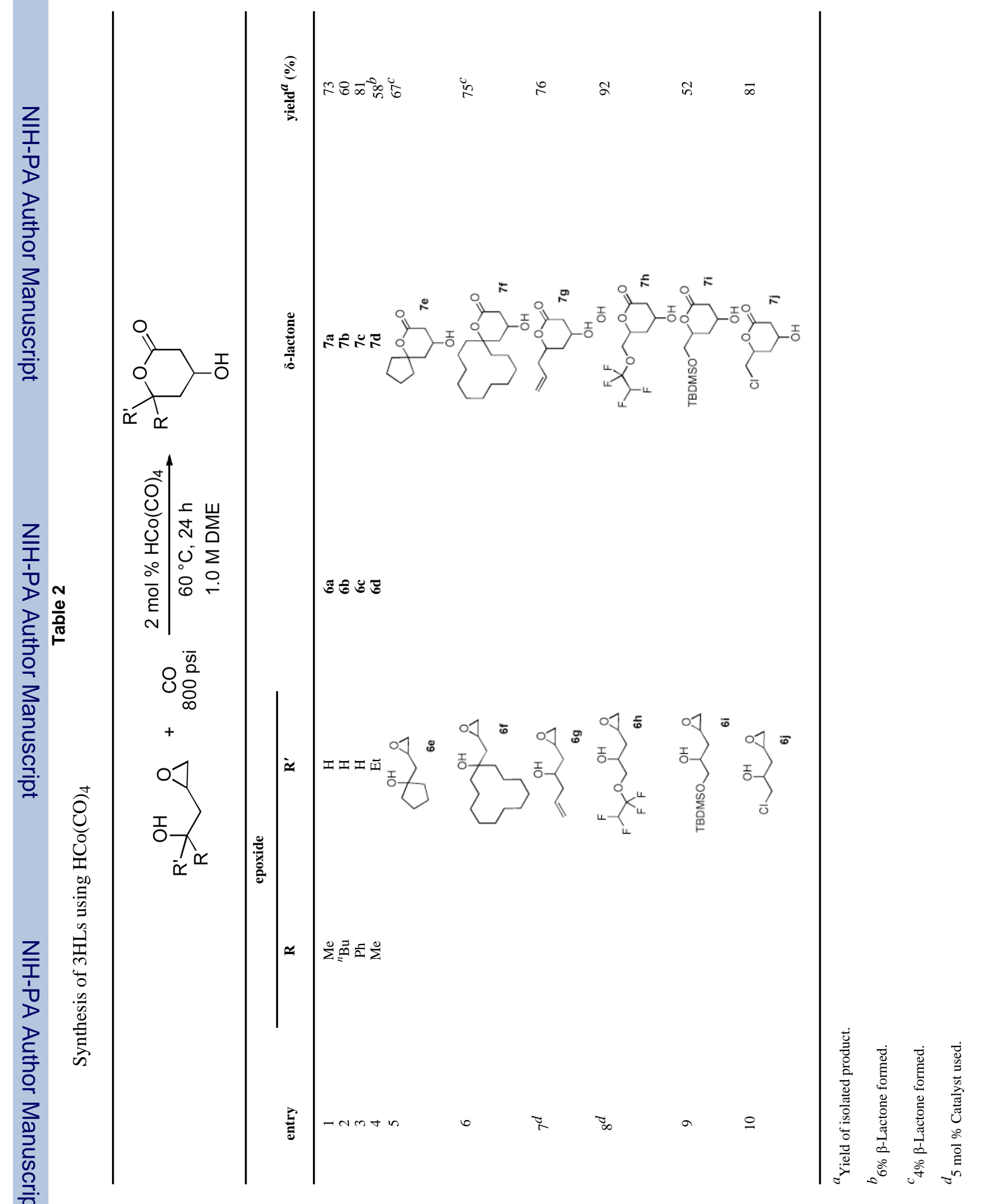

